\title{
Cultivo contínuo da cana-de-açúcar e modificações químicas de um Argissolo Amarelo fragipânico
}

\author{
Joselanne Luiza Trajano Maia ${ }^{(1)}$ e Mateus Rosas Ribeiro(2)
}

\begin{abstract}
(1)Embrapa Semi-Árido, Caixa Postal 23, CEP 56302-970 Petrolina, PE. E-mail: luizatm@cpatsa.embrapa.br (2)Universidade Federal Rural de Pernambuco, Dep. de Agronomia, Rua Dom Manoel de Medeiros, s/no, Dois Irmãos, CEP 52171-900 Recife, PE. E-mail: rosas@truenet.com.br

Resumo - O objetivo deste trabalho foi avaliar as modificações nas propriedades químicas de um Argissolo Amarelo fragipânico pelo cultivo contínuo com cana-de-açúcar. Em uma mesma situação topográfica de topo plano de tabuleiro costeiro, foram feitas coletas em três perfis: um perfil sob vegetação nativa ( $\mathrm{Tn}$ ) e os outros dois cultivados com cana-de-açúcar por períodos de dois e trinta anos. Os solos foram morfologicamente caracterizados e, nas amostras de cada horizonte, foram determinados $\mathrm{pH}$, carbono orgânico, fósforo assimilável, bases trocáveis, capacidade de troca catiônica, saturação por bases e saturação por alumínio. O manejo adotado no cultivo da cana-de-açúcar reduziu significativamente o cálcio, o magnésio, a saturação por bases, a capacidade de troca de cátions e o carbono orgânico, e aumentou o fósforo assimilável e a saturação por alumínio.
\end{abstract}

Termos para indexação: propriedades químicas, cultivo contínuo, cana-de-açúcar.

\section{Continuous sugarcane cropping and chemical modifications of a Fragiudult}

\begin{abstract}
The objective of this experiment was to evaluate the modifications on the chemical properties of a Fragiudult caused by continuous sugarcane cropping. In the same flat topographic position, three sites were selected, involving a native forest and sugarcane fields cultivated for periods of two and thirty years. The soils were morphologically characterized and samples were taken from each horizon to determine $\mathrm{pH}\left(\mathrm{H}_{2} \mathrm{O}\right.$ and $\left.\mathrm{KCl}\right)$, organic carbon, extractable phosphorus, exchangeable bases, cation exchange capacity, base saturation and aluminum saturation. The soil management adopted in the sugarcane cropping led to significant reduction of calcium, magnesium, base saturation, cation exchange capacity and organic carbon, and increased phosphorus and aluminum saturation.
\end{abstract}

Index terms: chemical properties, continuous cropping, sugarcane.

\section{Introdução}

As propriedades químicas dos solos são bastante modificadas com a retirada da vegetação natural e o cultivo, principalmente na camada arável, em virtude da adição de corretivos e fertilizantes e de operações agrícolas. Estas alterações dependem de vários fatores, como a cultura implantada e o manejo utilizado, a classe e a fertilidade inicial do solo, o comportamento físicoquímico de cada nutriente e suas interações com o meio (Sanches, 1998). Em diversos trabalhos, foi constatada acumulação dos cátions trocáveis na camada superior de solos cultivados, sendo esse acréscimo atribuído à aplicação de matéria orgânica (Silva \& Ribeiro, 1995) e calcário (Centurion et al., 1985).

As principais modificações nos solos cultivados, em relação às condições originais, decorreram do aumento do $\mathrm{pH}$ e dos teores de cátions, os quais foram depen- dentes da fertilidade inicial, ou seja, solos eutróficos diminuíram a fertilidade e os álicos aumentaram (Goldin \& Lavkulich, 1988). Sanchez (1985) e Silva \& Ribeiro (1995) encontraram aumentos do $\mathrm{pH}$ do solo com o tempo de cultivo e atribuíram este fato à aplicação de calcário ou à queima (Cadima et al., 1982, 1985), já que esta operação propicia aumento nos conteúdos de $\mathrm{Ca}, \mathrm{Mg}$ e K do solo (Nye \& Greenland, 1964).

A capacidade de troca de cátions (CTC) dos solos sob cultivo contínuo geralmente decresce com o tempo por, causa da diminuição da matéria orgânica na superfície (Sanchez et al., 1983; Cerri et al., 1991). Esses autores também observaram que a lixiviação dos cátions trocáveis em solos cultivados, acarretou um aumento relativo da CTC em profundidade. Aina (1979) constatou, em solos arenosos, que o cultivo ocasionou uma diminuição no $\mathrm{pH}$ do solo, além de uma menor CTC e teores mais baixos de $\mathrm{Ca}$ e $\mathrm{Mg}$ trocáveis. 
O cultivo contínuo tem alterado o conteúdo de $\mathrm{K}$ trocável na superfície do solo (Sparks et al., 1980; Sharpley \& Buol, 1987). De acordo com Cope (1981), em seis solos cultivados por dois anos sem receber fertilizantes potássicos, ocorreu decréscimo de $26 \%$ no conteúdo desse elemento, quando comparado com as condições originais.

Quando o ecossistema natural é substituído por uma cultura submetida a um manejo intensivo, como a canade-açúcar, o estoque de $\mathrm{C}$ do solo decresce substancialmente em relação ao sistema natural, não sendo recuperado (Cerri, 1986). Mais de 50\% da matéria orgânica previamente acumulada é perdida por diversos processos nos primeiros anos de cultivo, entre eles, a decomposição microbiana e a erosão (Greenland et al., 1992).

As superfícies aplanadas dos tabuleiros costeiros do Estado de Alagoas se destacam como uma importante área canavieira, onde os sistemas de produção com cultivo contínuo das terras, preparo excessivo do solo, elevado tráfego de máquinas e queima da palhada, previamente à colheita, podem causar degradação dos solos e reduzir a sua produtividade.

O objetivo deste trabalho foi avaliar as modificações nas propriedades químicas de um Argissolo Amarelo fragipânico, pelo cultivo contínuo com cana-de-açúcar.

\section{Material e Métodos}

O trabalho foi realizado em terras da usina Coruripe, no Município de mesmo nome, zona fisiográfica do litoral do Estado de Alagoas. Com base em um levantamento detalhado de solos (Usina Coruripe, 1997), foram selecionados três talhões representativos de áreas com vegetação nativa e cultivadas com cana-de-açúcar por diferentes períodos.

O solo foi classificado como Argissolo Amarelo distrófico abrupto fragipânico, A moderado, textura média/argilosa nas três áreas amostradas. Os perfis foram comparados entre si e em relação a uma testemunha absoluta, representada por solo em condições naturais (vegetação nativa), e receberam as identificações Tn, solo em condição natural, T2, solo com dois anos de cultivo com cana-de-açúcar, e T30, solo com trinta anos de cultivo com cana-de-açúcar. Os perfis ocupam uma mesma situação topográfica de topo plano de baixo Platô Costeiro.

Nas áreas cultivadas, as práticas de manejo ado tadas incluem, no momento do primeiro plantio e a cada seis anos, na renovação do canavial, correção da acidez, gradagem e subsolagem, seguida de plantio de leguminosa, que é incorporada posteriormente por meio de gradagem, sendo então feito o sulcamento, adubação com N-P-K, de acordo com a análise de solo, e plantio. Anualmente, após a colheita da cana-de-açúcar queimada, é feita a subsolagem com aplicação de matéria orgânica (composto) e adubação e, nos últimos dois anos, a área T30 recebeu $350 \mathrm{~m}^{3} \mathrm{ha}^{-1}$ ano $^{-1}$ de vinhaça em duas aplicações.

Em cada área estudada foi aberta uma trincheira, complementada por quatro tradagens dos três primeiros horizontes $(\mathrm{A}, \mathrm{AB}$ e $\mathrm{Bt})$, totalizando cinco repetições por tratamento. Após a descrição morfológica dos perfis, foram coletadas amostras em todos os horizontes até a profundidade de 1,6 $\mathrm{m}$. As amostras foram secadas ao ar, destorroadas e passadas em peneiras de $2 \mathrm{~mm}$ para obtenção da TFSA (terra fina secada ao ar). As analises químicas das amostras de solo foram realizadas conforme Embrapa (1997).

As alterações das propriedades do solo com o tempo de cultivo e com a profundidade foram estudadas por meio do esquema fatorial $3 \times 3$, correspondente a uma parcela de referência $(\mathrm{Tn})$, dois diferentes tempos de cultivo (T2 e T30) e três profundidades (horizontes A, $\mathrm{AB}$ e $\mathrm{Bt}$ ), e analisadas por meio de um delineamento inteiramente casualizado (Silva \& Silva, 1995). Quando o tempo de cultivo ou a profundidade, bem como a interação entre eles, foram significativos pelo teste $\mathrm{F}$, a comparação das médias foi feita pelo teste de Tukey a $5 \%$ de probabilidade, usando-se o software SAS (SAS Institute, 1999).

\section{Resultados e Discussão}

$\mathrm{O} \mathrm{pH}$ dos solos variou de 5,0 a 5,8 ao longo dos perfis, caracterizando que todos são ácidos (Tabela 1). Não houve alterações significativas do $\mathrm{pH}$ em água com o cultivo, e em profundidade, o $\mathrm{pH}$ diferiu significativamente no Bt (Tabela 1). As reduções do $\mathrm{pH}$ em conseqüência do cultivo são frequientemente observadas alguns anos após o desmatamento e queima em meio tropical. Estes resultados corroboram os de Sourabié (1979) e Cerri (1986). Com o cultivo mais prolongado, observou-se elevação de $\mathrm{pH}$ do horizonte superficial, em virtude da aplicação de corretivos e adição de vinhaça, que têm a propriedade de elevar o $\mathrm{pH}$ dos solos (Orlando Filho et al., 1983; Camargo et al., 1987; Fontes, 1989; Silva \& Ribeiro, 1998). 


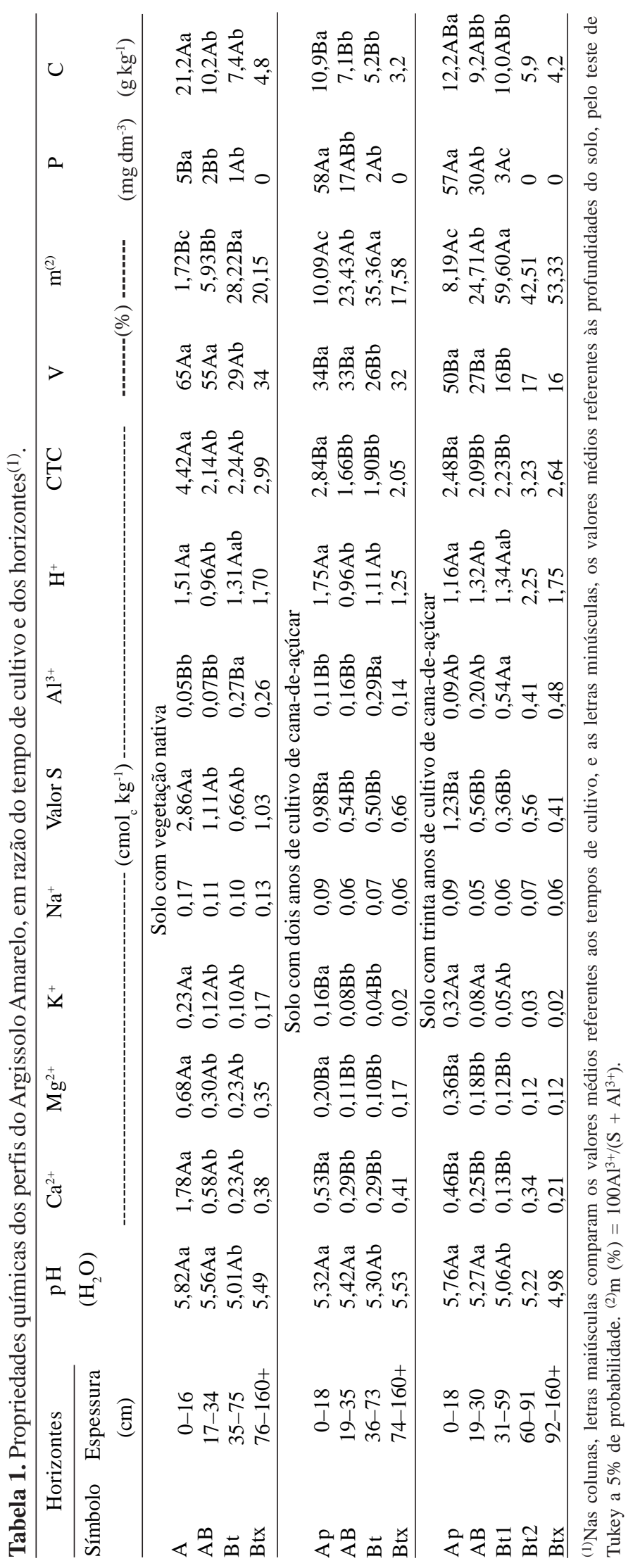

Pesq. agropec. bras., Brasília, v.39, n.11, p.1127-1132, nov. 2004 
O Al trocável aumentou significativamente com a profundidade do solo e com o tempo de cultivo (Tabela 1). Houve aumento significativo no perfil T30, provavelmente por causa das perdas de bases, seja por lixiviação ou por absorção pela cana-de-açúcar.

A saturação por Al apresentou comportamento semelhante ao Al trocável, mostrando interações significativas com o tempo de cultivo e com a profundidade, chegando a atingir no Bt, 35,4\% no perfil T2 e 59,6\% no perfil T30 (Tabela 1). Segundo Rodella et al. (1984), este valor está acima do nível crítico (25\%) estabelecido para a cana-de-açúcar. Estes resultados foram contrários aos encontrados por Silva \& Ribeiro (1995), em Argissolos Amarelos latossólicos.

No perfil sob mata, o Ca foi, entre as bases trocáveis, o íon quantitativamente mais importante, decrescendo ao longo do perfil, seguido pelo $\mathrm{Mg}$ e o K trocáveis, observando-se diferenças significativas entre o horizonte A e os horizontes AB e Bt. Este mesmo comportamento foi observado nos solos cultivados (Tabela 1).

Os valores de $\mathrm{Ca}$ e $\mathrm{Mg}$ são maiores no perfil $\mathrm{Tn}$, observando-se uma redução significativa nos perfis dos solos sob cultivo (Tabela 1). No perfil T30, houve um aumento no teor de $\mathrm{K}$ em relação ao T2, provavelmente deecorrente à adição de vinhaça e adubação. A remoção dos conteúdos de $\mathrm{Ca}$ e $\mathrm{Mg}$ nos perfis cultivados, principalmente no horizonte A, deve ser resultante da absorção pelas plantas e lixiviação em virtude da textura arenosa do horizonte superficial destes solos. Estes resultados também foram observados por Sanches (1998) em Podzólicos Vermelho-Amarelo, Aina (1979) em solos arenosos, e por Goldin \& Lavkulich (1988) e Lepsch et al. (1994) em solos eutróficos.

Houve um decréscimo na relação $\mathrm{Ca} / \mathrm{Mg}$ no solo T30, o que deve influir nos processos de assimilação dos nutrientes. Esta relação seria um parâmetro a ser considerado como conseqüência do manejo intensivo do solo. Normalmente, o que se espera em solos cultivados por longo tempo, nos quais são utilizados fertilizantes, calcário e vinhaça, é o aumento das bases trocáveis, principalmente no horizonte A, como observado por Camargo et al. (1983) e Silva \& Ribeiro (1995, 1998).

Todos os perfis possuem baixos valores de saturação por bases (V), sendo classificados segundo Embrapa (1999) como solos distróficos. Nos três perfis, a saturação por bases decresceu com a profundidade (Tabela 1). Os resultados do perfil de mata comparados com os cultivados indicam que a saturação por bases diminuiu significativamente com o desmatamento e o culti- vo, mesmo recebendo aplicações de corretivos e fertilizantes (T2 e T30) e aplicação de vinhaça (T30). Nos perfis, o horizonte Bt diferiu significativamente dos demais. À medida que se reduziu a saturação por bases, o pH também diminuiu, numa proporção mais ou menos definida. A acentuada redução em bases trocáveis pode estar associada à redução da matéria orgânica e à remoção de cátions, principalmente o Ca e o Mg.

A capacidade de troca de cátions (CTC) variou de 1,67 a 4,41 $\mathrm{cmol}_{\mathrm{c}} \mathrm{kg}^{-1}$ solo, considerada como muito baixa e compatível com a mineralogia caulinítica dos Argissolos Amarelos de tabuleiros (Tabela 1). A CTC está relacionada com a atividade e o conteúdo da matéria orgânica, sendo maior no solo da mata, concordando com o maior teor carbono. A CTC apresentou redução principalmente no $\mathrm{T} 2$, que por causa do desmatamento e cultivo, sofreu uma rápida redução dos níveis de matéria orgânica. Resultados semelhantes foram obtidos por Aina (1979), Sanchez et al. (1983), Silva \& Ribeiro (1998) e Sanches (1998).

Nos perfis, o cátion $\mathrm{H}^{+}$foi o íon quantitativamente mais importante da CTC, excetuando-se no horizonte A do perfil Tn. $\mathrm{O} \mathrm{H}^{+}$não difere com o tempo de cultivo e sim com a profundidade, tendo seu maior valor no horizonte A ou Ap (Tabela 1).

De modo geral, os teores de P assimilável no solo são baixos, o que se deve, especialmente, à pequena quantidade desse elemento nas rochas ou materiais de origem do solo. Todo o P assimilável presente no solo sob vegetação natural (Tn) está localizado no horizonte superficial, provavelmente por causa da reciclagem e mineralização de compostos orgânicos, e decresce significativamente no horizonte $\mathrm{AB}$, acompanhando a redução da matéria orgânica (Tabela 1). Nos perfis cultivados, os teores de $\mathrm{P}$ assimilável foram mais altos, mas, também decresceram de forma significativa no horizonte AB do T2 e T30, e no Bt do T30. Os valores de P disponível ao longo dos perfis T2 e T30 são resultantes da aplicação de fertilizantes, o que também foi constatado por Cerri (1986) e Silva \& Ribeiro (1995, 1998).

$\mathrm{O}$ conteúdo de $\mathrm{C}$ diminuiu com a profundidade ao longo de todos os perfis; ficando este comportamento logo evidenciado no horizonte $\mathrm{AB}$, que mostra um decréscimo significativo em relação ao A (Tabela 1). Quanto ao tempo de cultivo, houve um decréscimo significativo do conteúdo de C no T2 e T30, com exceção do horizonte $\mathrm{Bt}$ do $\mathrm{T} 30$. Esta perda de $\mathrm{C}$ no $\mathrm{T} 2$ se deve à remoção mecanizada da vegetação natural e à rápida 
decomposição da matéria orgânica. Isto resultou da quebra do equilíbrio do ecossistema natural nos primeiros anos de cultivo, com conseqüente diminuição da matéria orgânica. No perfil T30, observou-se que o solo adaptou-se a um novo equilíbrio, em decorrência das práticas de manejo adotadas ao longo de 30 anos e aplicação de vinhaça nos últimos dois anos. Entretanto, seus valores ainda são menores que os do solo de mata, porém, maiores que os do solo com dois anos de cultivo. $\mathrm{O}$ pequeno aumento de $\mathrm{C}$ no $\mathrm{Bt}$ do $\mathrm{T} 30$ também seria resultante das práticas de manejo adotadas ao longo de 30 anos. Resultados também encontrados por Silva \& Ribeiro (1998).

\section{Conclusões}

1. O manejo adotado no cultivo da cana-de-açúcar afeta negativamente as propriedades químicas dos solos.

2. Com o tempo de cultivo, há redução significativa do cálcio, magnésio, saturação por bases, capacidade de troca de cátions e carbono orgânico.

3. Ocorre um aumento significativo de fósforo disponível e da saturação por alumínio, com o tempo de cultivo e com a profundidade.

\section{Agradecimentos}

Ao CNPq (Conselho Nacional de Desenvolvimento Científico e Tecnológico), pela concessão de bolsa a Mateus Rosas Ribeiro.

\section{Referências}

AINA, P.O. Soil changes resulting from long-term management practices in Western Nigeria. Soil Science Society of America Journal, v.43, p.173-177, 1979.

CADIMA, Z.A.; SILVA, L.F. da; LOBÃO, D.E.P. Alterações edáficas provocadas por um sistema de agricultura itinerante em solos de tabuleiros no Sul da Bahia. Revista Theobroma, v.2, p.267272, 1982.

CADIMA, Z.A.; SILVA, L.F. da; LOBÃO, D.E.P. Efeito da queima e adubação em solos de tabuleiros (Haplorthox) sob consorciação milho-feijão. Revista Theobroma, v.15, p.101-112, 1985.

CAMARGO, M.N.; KLAMT, E.; KAUFFMAN, J.H. Classificação de solos usada em levantamentos pedológicos no Brasil. Boletim Informativo da Sociedade Brasileira de Ciência do Solo, v.16, p.11-33, 1987.

CAMARGO, O.A.; VALADARES, J.M.A.S.; GERARDI, R.N. Características químicas e físicas de solo que recebeu vinhaça por longo tempo. Campinas: IAC, 1983. 30p. (IAC. Boletim Técnico, 76).
CENTURION, G.M.; DEMATÊ, J.L.I.; FERNADES, P.M. Efeito de sistemas de preparo nas propriedades químicas de um solo sob cerrado cultivado com soja. Revista Brasileira de Ciência do Solo, v.9, p.267-270, 1985.

CERRI, C.C. Dinâmica da matéria orgânica do solo no agroecossistema cana-de-açúcar. 1986. 187p. Tese (Livre Docência) - Escola Superior de Agricultura Luiz de Queiroz, Piracicaba.

CERRI, C.C.; FELLER, C.; CHAUVEL, A. Evolução das principais propriedades de um Latossolo Vermelho-Escuro após desmatamento e cultivo por doze e cinquienta anos com cana-de-açúcar. Cahiers Orstom, Série Pédologie, v.26, p.37-50, 1991.

COPE, J.T. Effects of 50 years of fertilization with phosphorus and potassium on soil test levels and yields at six locations. Soil Science Society of America Journal, v.45, p.342-347, 1981.

EMBRAPA. Centro Nacional de Pesquisa de Solos (Rio de Janeiro, RJ). Manual de métodos de análises de solo. 2.ed. rev. atual. Rio de Janeiro, 1997. 212p.

EMBRAPA. Centro Nacional de Pesquisa de Solos (Rio de Janeiro, RJ). Sistema brasileiro de classificação de solos. Brasília: Embrapa-SPI; Embrapa-CNPS, 1999. 412p.

FONTES, L.E. Propriedades físicas e químicas de um Latossolo Vermelho-Escuro de Goianésia, GO, cultivado com cana-deaçúcar e irrigado com vinhaça. 1989. 76p. Tese (Doutorado) Universidade Federal de Viçosa, Viçosa.

GOLDIN, A.; LAVKULICH, L.M. Historical land clearing in the fraser lowland of Bristish Columbia and Washington State: 1. Effects on soil genesis. Soil Science Society of America Journal, v.52, p.467-473, 1988 .

GREENLAND, D.J.; WILD, A.; ADAMS, D. Organic matter dynamics in soils of the tropics-from myth to complex reality. In: LAL, R. (Ed.). Myths and science of soils of the tropics. Madison: ASA; SSSA, 1992. p.17-33.

LEPSCH, I.F; MENK, J.R.F.; OLIVEIRA, J.B. Carbon storage and other properties of soils under agriculture and natural vegetation in São Paulo State, Brazil. Soil Use and Management, v.10, p.34-42, 1994.

NYE, P.H.; GREENLAND, D.J. Changes in the soil after clearing tropical forest. Plant and Soil, v.21, p.101-102, 1964.

ORLANDO FILHO, J.; ZAMBELO JUNIOR, E.; AGUJARO, R.; ROSSETO, A.J. Efeito da aplicação prolongada de vinhaça nas propriedades químicas dos solos com cana-de-açúcar. Estudo Exploratório. STAB, v.1, p.28-33, 1983.

RODELlA, A.A.; ZAMBELLO JUNIOR, E.; ORDO, F.O.J. Calibração de cálcio, magnésio e acidez do solo para cana-de-açúcar cultivada na região de cerrado. STAB, v.2, p.45-48, 1984.

SANCHES, A.C. Alterações nas propriedades de um Podzólico Vermelho Amarelo resultantes da substituição da mata natural pela cultura da laranja. 1998. 49p. Dissertação (Mestrado) Escola Superior de Agricultura Luiz de Queiroz, Piracicaba.

SANCHEZ, P.A. Fertilizers make continuous cropping possible in the Amazon. Better Crops International, v.1, p.12-33, 1985. 
SANCHEZ, P.A.;VILLACHICA, J.H.; BANDY, D.E. Soil fertility dynamics after clearing a tropical rainforest in Peru. Soil Science Society of America Journal, v.47, p.1171-1178, 1983.

SAS INSTITUTE (Cary, Estados Unidos). SAS/STAT user's guide: version 8. Cary, 1999. 1243p.

SHARPLEY, A.N.; BUOL, S.W. Relationship between minimum exchangeable potassium and soil taxonomy. Communications in Soil Science and Plant Analysis, v.18, p.601-614, 1987.

SILVA, A.J.N. da; RIBEIRO, M.R. Características de um Latossolo Amarelo sob cultivo contínuo da cana-de-açúcar no Estado de Alagoas: propriedades químicas. Revista Brasileira de Ciência do Solo, v.22, p.291-299, 1998.

SILVA, J.A.A. da; SILVA, I.P. da. Estatística experimental aplicada à Ciência Florestal. Recife: Imprensa Universitária, UFRPE, 1995. 296p.
SILVA, M.S.L. da; RIBEIRO, M.R. Influência do cultivo contínuo da cana-de-açúcar nas propriedades químicas de solos argilosos. Pesquisa Agropecuária Brasileira, v.30, p.389-394, 1995.

SPARKS, D.L.; MARTENS, D.C.; ZALAZNY, L.W. Plant uptake and leaching of applied and indigenous potassium in Dothan soils. Agronomy Journal, v.72, p.551-555, 1980.

SOURABIÉ, N. Influence de la culture de la canne à sucre sur les sols de Bérégadougou (Hante Volta). Cas particulier des facteurs de fertilité liés a la matiére organic. 1979. 190p. These Université Aix Marseille, Marseille.

USINA CORURIPE (Coruripe, AL). Levantamento detalhado de solos da Usina Coruripe. Coruripe, 1997. 47p.

Recebido em 25 de maio de 2004 e aprovado em 27 de outubro de 2004 